\title{
Cairene Colloquial Arabic and English Syllable Structures and Implications for L2 English Syllable Acquisition
}

\author{
Mohamed Fathy Khalifa \\ Assistant Professor of Linguistics \\ Department of Teaching English as a Foreign Language \\ Faculty of Education and Basic Sciences \\ Ajman University \\ UAE
}

\begin{abstract}
Syllable structure plays a crucial rule in the production of language and varies considerably from one language to another. The differences between syllable structures of the first language (L1) and the second language (L2) can be sources of L2 errors and lead to syllable repair strategies which bring the L2 syllable structure into conformity with the L1. This research paper discusses the similarities and differences between Cairene Colloquial Arabic (CCA) and English syllable structures and explains implications for L2 English acquisition by CCA speakers. CCA and English syllable structure constituents and their phonotactic constraints are compared and show that CCA onsets, nuclei and codas are subsets of corresponding English syllable constituents. Therefore, CCA speakers attempt to apply the CCA syllable structure assignment rules to English strings. This syllable structure transfer explains certain errors of CCA speakers learning English.
\end{abstract}

Keywords: Cairene Colloquial Arabic syllable structure, English syllable structure, L2 Englsih syllable acquisition, CCA and English syllable types, syllable weight, rime structure, negative transfer

\section{Introduction}

\subsection{The Syllable: Definition and Structure}

The syllable has been written about extensively in linguistic theory, and the material covered in this paper only touches the tip of the iceberg. According to Al-Ani and May $(1973,113)$, 'the syllable is, indeed, one of the most controversial topics in linguistics today....the question of the syllable's existence in every language is, of course, crucial, for if its absence from only one language can be proved, then the case that the syllable is a linguistic universal is forever lost'. The syllable is the most widely discussed phonological suprasegmental and linguistic construct which has been recognised as a significant unit in phonological representation (Selkirk, 1982). This is pointed out by Goldsmith $(1990,101)$ who states that 'the syllable is a unit of phonological description which has never ceased to be discussed al length in the phonological literature of this century'. In generative phonology, the syllable is considered as an essential concept for understanding phonological structure (Chomsky and Halle, 1968). Goldsmith $(2011,165)$ points out that 'the syllable is one of the oldest constructs in the study of language, and most studies of phonology have found a place for the syllable within them'.

The syllable is a basic unit of speech which is studied on both the phonetic and phonological levels of analysis (Al-Ani and May, 1973). Although it can be easy for people and even for children to count the number of syllables in a sequence in their native language, there is no universal agreement upon the phonetic definition of a syllable (Spencer, 1996). However, it is clear that the structure of syllables is often of considerable importance for the phonological organization of the language. This is pointed out by Blevins $(1995,206)$ who states that 'the role of the syllable in phonological theory has become more significant with each passing decade....all major approaches to phonology ... have recognized the syllable as a fundamental unit in phonological analysis'.

The syllable has proved exceedingly difficult to define. This is explained by Crystal $(1997,374)$ who states that 'providing a precise definition of the syllable is not an easy task, and there are several theories in both PHONETICS AND PHONOLOGY which have tried to clarify matters. From a phonetic viewpoint, attempts have been made to define the syllables of a LANGUAGE on the basis of the articulatory effort needed in order to produce them....Phonological views of the syllable, on the other hand, focus on the ways sounds combine in 88 
individual languages to produce typical SEQUENCES'. Some linguists' views about the phonetic and phonological definitions of the syllable will be explained briefly below. In addition, some of the theories dealing with the syllable will be discussed below.

There have been various attempts to define the syllable phonetically: as a single respiratory movement (the chestpulse theory), as a single opening and closing of the vocal tract, as a single peak of prominence in the soundstream resulting from a combination iof stress, pitch, length and intrinsic sonority (the prominence theory). According to Roach $(2000,70)$, phonetically, syllables 'are usually described as consisting of a centre which has little or no obstruction to airflow and which sounds comparatively loud; before and after that centre (...) there will be greater obstruction to airflow and/or less loud sound'. For example, in the monosyllabic word $c u t / k \Lambda t /$, the vowel $/ \Lambda /$ is the centre at which little obstruction takes place, whereas there is complete obstruction to the airflow for the surrounding plosives $/ \mathrm{k} /$ and $/ \mathrm{t} /$. However, none of the above attempts has proved unsustainable.

According to Hooper (1972, 525), 'the syllable is an important phonological unit that must be defined formally within generative phonology. Evidence from Spanish, German, and other languages shows that a syllable boundary is necessary to designate the domain of certain phonological rules'. Goldsmith $(2011,195)$ explains that 'phonologists have long hoped to simplify the overall phonological description of possible words by viewing words as being built up of smaller phonological units, notably the syllable'. Blevins $(1995,207)$ defines the syllable phonologically as 'phonological unit which organizes segmental melodies in terms of sonority; syllabic segments are equivalent to sonority peaks within these organizational units'. The phonological syllable is also defined by Laver $(1994,114)$ as 'a complex unit made up of nuclear and marginal elements'. The vowels or syllabic segments represent nuclear elements whereas the consonants or non-syllabic segments make up the marginal elements. In the syllable faint /feint/, the nuclear element is represented by the diphthong /ei/ whereas the marginal elements are represented by initial consonant /f/ and the final consonant cluster /nt/. Trask (1996, 344) points out that two syllable definition approaches dominate: '(1) the syllabe is a unit of neural programming which can be reconstructed by the hearer from a variety of clues, in spite of absence of any single phonetic correlate; (2) the syllable is a purely phonological unit consisting of a single peak of intrinsic sonority, though with qualifications for cases like English spit, which has two peaks'. According to Goldsmith $(2011,166)$, 'the study of the syllable in recent decades has been an integral part of the development of theories of rules, constraints, and their interactions'. Pike $(1947,144)$ noted that the syllable was 'the basic structural unit which serves as a point of reference for describing the distribution of the phonemes in the language in question'. Pulgram $(1970,21)$ states that the syllable 'has no function, no raison d'etre, apart from that of the syllabic segmentation of an utterance'.

There have been different attempts to provide physiological, acoustic or auditory explanations and definitions of the syllable. For example, the 'prominence theory' which is based mainly on auditory judgements states that the number of syllables in a word is determined by the number of peaks of prominence. In the word entertainment /entə'teInmont/, the peaks of prominence are represented by the vowels /e ə ei ə/. However, this theory only shows the position of the nucleus which is the prominence peak, but it does not help much in discussions of syllable division.

Another attempt is the 'chest pulse theory' which discusses the syllable in the context of muscular activities and lung movements in the process of speech. Experiments have shown that the number of chest pulses, accompanied by increase of air pressure can determine the number of syllables produced (Gimson, 1970). This allows the association of the number of syllables with the number of chest pulses. However, this approach cannot account for cases of two consecutive vowels. For example, in words like doing /'du:In/ or staying /sterny/, since the second chest pulse might be almost unnoticeable, it could lead to the erroneous conclusion that there is only one syllable instead of two in such English words.

The 'sonority theory' presents another approach in which the pulses of pulmonic air stream in speech 'correspond to peaks in sonority' (Giegerich, 1992, 132). The sonority of speech sound is discussed as 'its relative loudness compared to other sounds' (ibid) and each syllable corresponds to a peak in the flow rate of pulmonic air. Therefore, nuclear elements or syllabic segments can be considered as intrinsically more sonorous than marginal or non-syllabic elements. However, like all the approaches outlined above, the sonority theory is of little help in delimiting separate syllables. 
Although there are different views among linguists for the definition and function of the syllable in phonological theory, they all agree in using the syllable in the description of languages. There are three types of evidence for the syllable as a structural unit as follows:

1) The syllable provides a domain for some phonotactic constraints (Goldsmith, 2011).

a. Pike (1947), Fudge (1969), Kahn (1976) and Selkirk (1982) state that the syllable must be related to phoneme distribution.

b. According to Pulgram (1970), the syllable should be defined as a build-up of phonemes that are aligned according to certain phonetic rules. For example, in English the sequences /sw/ and /skr/ are allowed initially, while the sequences $/ \mathrm{lk} /$ and $/ \mathrm{mp} /$ are not.

2) The syllable is a domain for some phonological rules such as epenthesis and deletion which can be simply and accurately expressed by explicit reference to the syllable.

a. Hooper (1972) argues for a syllable-based analysis of nasal and lateral assimilation and s-voicing in Spanish.

b. According to Kahn (1976), some low-level processes in English, aspiration, glottalization and voicing of /t/ in American English can be analysed only through syllable structure.

3) The syllable can facilitate explanation of prosodic phonological processes such as stress, nasalisation and quantity (Selkirk, 1982).

a. Goldsmith (1976) states that since prosodic phenomena such as stress affect syllables rather than single segments, morphemes or words, the domain on which such units are defined must be the syllable.

b. According to Broselow (1979), the minimum domain for emphasis in Cairene Arabic is not the segment but the syllable.

According to Clements and Keyser (1983), any syllable theory has to achieve three objectives: (a) specify universal principles governing syllable structure (b) set a syllable structure algorithm which may vary from one language to another and (c) define language-specific rules governing syllable structure.

\subsection{Syllable Structure}

A syllable is a unit of sound composed of a central peak of sonority (usually a vowel) and the consonants that may cluster around this central peak. Syllable structure is a language-specific combination of allowable segments and sound sequences. This is pointed out by Goldsmith $(2011,170)$ who states that 'syllable structure is probably the single most important conditioning environment for segmental rules'. The current phonological theories agree that the syllable has constituent or hierarchical rather than linear structure. This is pointed out by Selkirk (1982, 337338) who states that 'the syllable is an element of a hierarchically organized prosodic structure'.

The syllable has internal structure - two immediate constituents: the onset $(\mathrm{O})$ which includes any consonants that precede the nuclear element (the vowel), and the rime $(\mathrm{R})$ which includes the nuclear element and any marginal consonants that follow it. The rime is divided into nucleus $(\mathrm{N})$ and coda $(\mathrm{Cd})$ (Selkirk, 1982). The nucleus represents the most sonorous element in a syllable and the coda includes all the consonants that follow the nucleus. This structure of syllables is represented by Goldsmith $(2011,180)$ as follows.

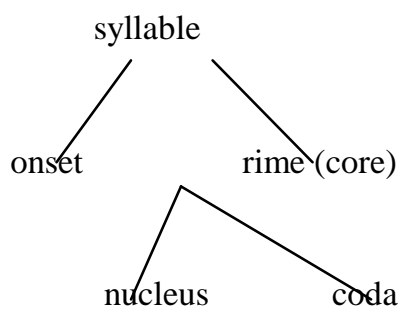

(peak) Syllable structure may be represented graphically by means of a 'tree diagram' as shown for the English word hat and the CCA word /walad/ boy. 
(2)

a.

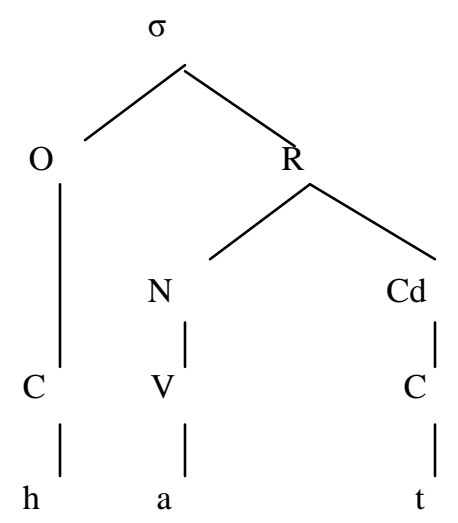

b.
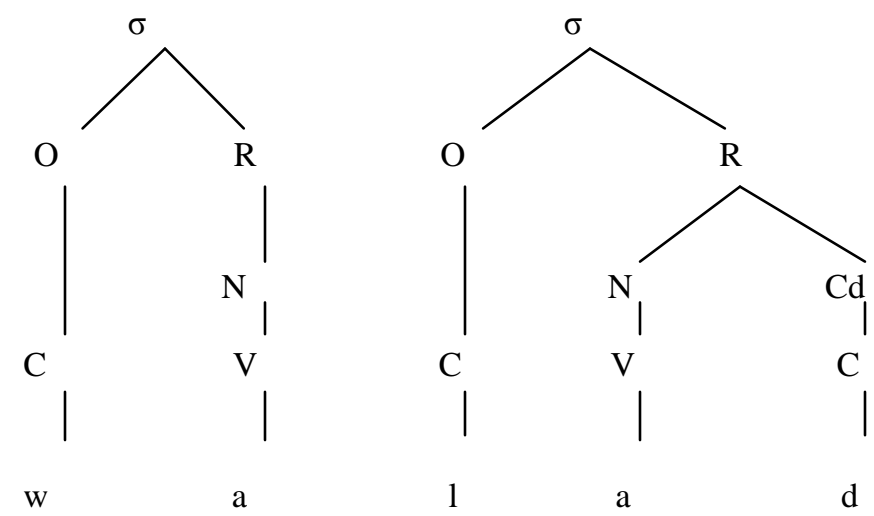

However, there are syllables in English without onsets or codas - only the nucleus is an obligatory element in all languages. The different parts of the syllable and their optional or obligatory status are explained in the following table.

Table 1: Parts of the Syllable

\begin{tabular}{|l|l|l|}
\hline Part & Description & Optionality \\
\hline \hline Onset & Initial segment of a syllable & Optional \\
\hline Rime & $\begin{array}{l}\text { The core of the syllable consisting of a } \\
\text { nucleus and a coda }\end{array}$ & Obligatory \\
\hline Nucleus & $\begin{array}{l}\text { Central segment of the syllable - usually a } \\
\text { vowel }\end{array}$ & Obligatory \\
\hline Coda & Final segment of a syllable & Optional \\
\hline
\end{tabular}

This shows that it is possible for a syllable to be onsetless as in some English words such as above, entry, inside and origin. The onset is the sister constituent of the rime. But it is not possible to find any well-formed syllable without a rime. Rime is the only obligatory constituent of the syllable. Goldsmith $(1990,4)$ points out that 'the syllable is subject to well-formedness conditions as well regarding the complexity of each of its components, such as the onset and the rhyme'. The different parts of the syllable and their parameters will be discussed below.

\section{The Onset}

Whenever possible consonants are syllabified as onsets, for example, an intervocalic consonant is universally syllabified as an onset to the second syllable, not a coda to the first syllable. This shows that all consonants have a chance to become an onset first and only end up as a coda as a last resort. Languages can differ regarding the possible onsets - some languages allow only one consonant in the onset whereas others allow consonant clusters subject to language-specific phonotactic rules.

Onset parameters:

- onset (compulsory/optional)

- onset clusters allowed? (yes/no)

- if yes, any restrictions? 


\section{The Nucleus}

Syllable nuclei vary from one language to another. All languages allow a single vowel to be a nucleus and some also allow a two-vowel nucleus. Although the nucleus is mainly represented by vowels, other languages permit particular types of consonants to be nuclei. English allows both kinds of nuclei.

Nucleus Parameters:

- V nucleus allowed (universal)

- VV nucleus allowed? (yes/no)

- if yes, any restrictions?

- C nucleus allowed? (yes/no)

- if yes, any restrictions?

\section{The coda}

Not every language has syllables with codas as part of its system of syllabification rules. This shows that coda is not a universal part of syllabification. Like onsets, languages can differ in allowing coda clusters and the restrictions on these clusters.

Coda parameters:

- coda allowed? (yes/no)

- if yes, any restrictions?

- coda clusters allowed? (yes/no)

- if yes, any restrictions?

There are various types of syllables in different languages. The CV syllable is the core syllable which occurs in all languages (Blevins, 1995). As stated by Malmberg (1963, 129), 'a syllable consisting of a consonant plus a vowel represents the most primitive, and without doubt historically the oldest, of all syllable types, the only one which is general in all languages'. The core syllable CV is simplest, the VC syllable is the most complex, the two other syllables (V and CVC) have intermediate complexity. This research includes three main sections. The first section explains the structure of English syllables and their types. The second section explains the structure of CCA syllables and their types. Third, a comparison of CCA and English syllable structures and implications for L2 English acquisition by CCA speakers are explained.

\section{CCA Syllable Structure}

CCA has many restrictions on syllable structures (Watson, 2002). For example, CCA syllables must start with one and only one consonant (Broselow, 1988) and the syllabic structure prevents three consonants or two vowels to appear adjacently. The CCA syllable structure constituents and their restrictions are now discussed.

\subsection{Onset}

In CCA, onsets are obligatory in the sense that no syllable can begin with a vowel. Thus CCA does not allow onset-less syllables, Broselow $(1984,256)$ states that in CCA 'each syllable must begin with one and only one consonant'. CCA also follows the Maximal Onset Principle, stated by Broselow $(1976,34)$ as follows: 'a single consonant followed by a vowel always shares syllable with that vowel', as shown below (NB. IPA transcriptions are used throughout).
(3) a. /muf.ta:h/
'key'
b. /mak.ta.ba/ 'library'
c. /sig.ga:.da/ 'carpet'
d. /fi.himt/ 'I understood'
e. /ka.ra:.si/ 'chairs'

In addition, CCA has a constraint on the syllabic structure which outlaws complex onsets (Broselow, 1992), as in /buxala/ misers and /maktab/ office. The syllable structure of these words is shown below: 
(4) a. 'buxala'
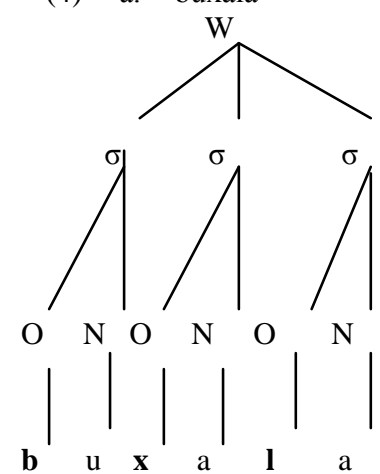

b. 'maktab'
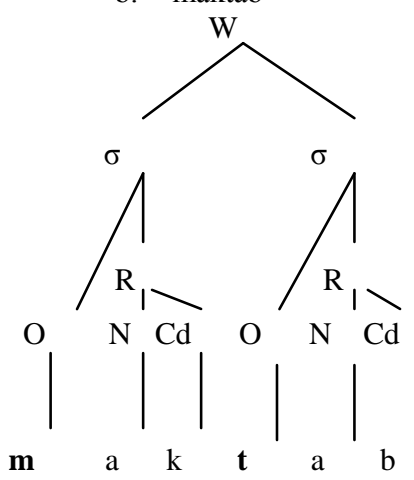

As a consequence, we cannot have words like blue, true, black, strange and spring in CCA.

Itô $(1989,223)$ proposes the Onset Principle, which requires onsetless syllables to be avoided:

(5) Onset Principle:

Avoid $\sigma[\mathrm{V}$

Since in all Arabic dialects, including CCA, onsets are obligatory, this principle can be changed to:

(6) Onset Principle:

Impossible $\sigma[\mathrm{V}$

In CCA only the forms in a) are acceptable syllabifications, but not the ones in b) or c):

(7) /bu.ju:t/ 'houses'

(7) /bu.ju:t/ 'houses'

a.

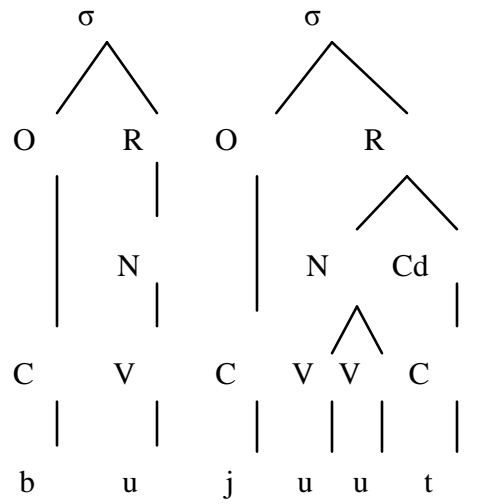

*b.

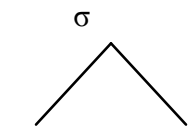

$\mathrm{O}$

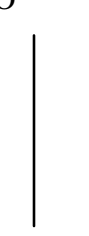

$\begin{array}{cccccc}C & V & C & V & V & C \\ b & u & j & \left.\right|_{u} \mid\end{array}$
$\mathrm{R}$

$\sigma$

R
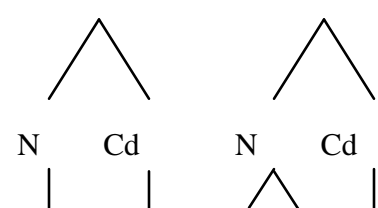

$$
\text { | }
$$


(8) /milaja:t/ 'sheets'

a.
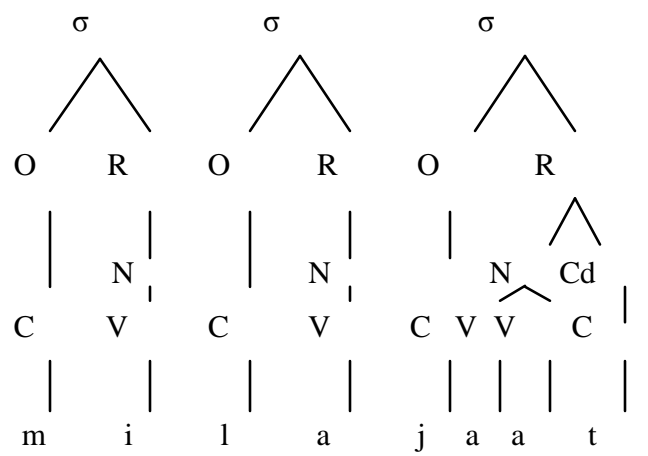

*b.

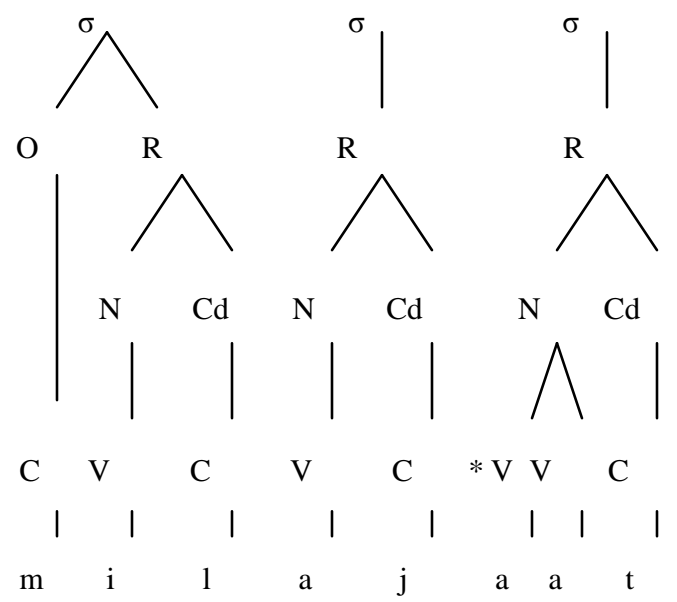

$*^{c}$.
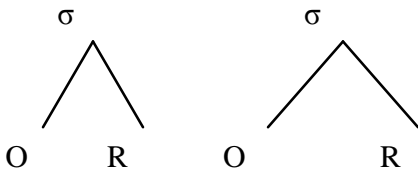

$\sigma$

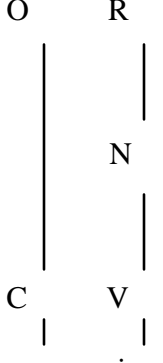

$\mathrm{O}$

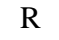

$\mathrm{R}$

(9) /da:fi/ 'warm'

a)
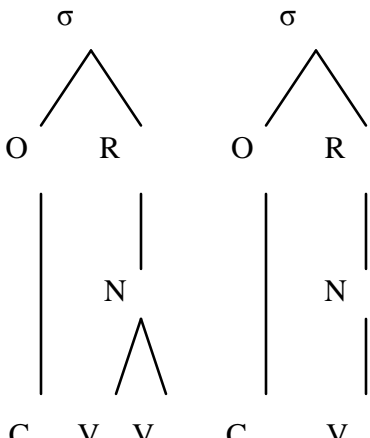

\begin{tabular}{lllll}
$C$ & V & V & C & V \\
\hline & $\mid$ & 1 & $\mid$
\end{tabular}

$\begin{array}{lllll}\text { d } & \text { a } & \text { a } & \text { f } & \text { i }\end{array}$ 
*b)

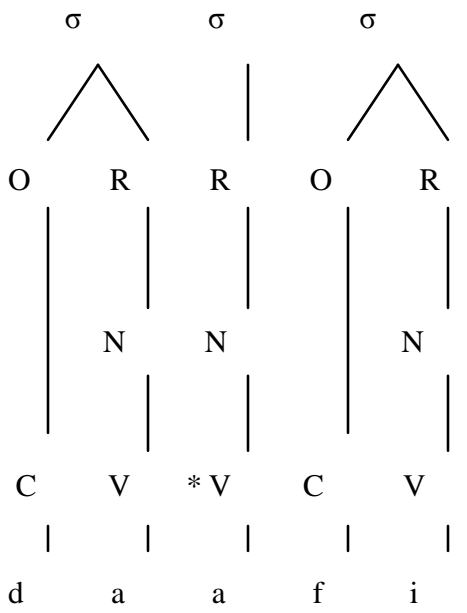

Onsetless syllables and complex onsets are banned absolutely in CCA.CCA Onset Template $\mathrm{O}[\mathrm{C}]$, hence $* \mathrm{O}[\mathrm{V}] \quad * \mathrm{O}[\mathrm{CC}]$

\subsection{Nucleus}

As in all languages, CCA syllables must have a nucleus which can be as follows:

- $\quad$ simple: it includes only one vowel as in /ma.li.ka/ queen and /mux.ta.li.fa/ different (f. sing.)

- complex: it includes a long vowel as in /mi:n/ who and /hu:t/ whale.

There are some restrictions on the CCA nucleus. First, this nucleus cannot be a consonant, such as the syllabic consonants in English. Second, a VV nucleus is not allowed in CCA, where VV is a diphthong, and V: is a long vowel.

CCA Nucleus Parameters:

- V nucleus allowed? (yes)

- VV nucleus allowed? (no) (but V: allowed)

- C nucleus allowed? (no)

CCA Nucleus Template:

$\mathrm{N}[\mathrm{V}] \quad \mathrm{N}[\mathrm{V}:]$ hence $* \mathrm{~N}[\mathrm{VV}]$

\subsection{Coda}

CCA coda can have one of the following forms:

- simple: it includes only one consonant as in /mak.tab/ office and /jif.ham/ he understands.

- complex: it includes two consonants, it only occurs in final position, as in /ward/ roses, /ku.rumb/ cabbages and $/ \mathrm{ka} \cdot \mathrm{tabt} / \mathrm{I}$ wrote.

The CCA coda thus has some restrictions, since it only allows one consonant in word medial position (Broselow, 1992), and not more than two consonants word finally.

CCA Coda Parameters:

- Coda allowed? (yes)

- Coda clusters allowed? (yes)

- Restrictions: Medial (not more than one consonant)

Final (not more than two consonants)

CCA Coda Template

$\mathrm{Cd}[\mathrm{C}] \quad \mathrm{Cd}[\mathrm{CC}]$, hence $* \mathrm{Cd}[\mathrm{CCC}]$

\subsection{Rime}

The CCA rime can have one of the following forms:

- non-branching: it includes only a nucleus with a short vowel as in /na. Sam/ yes.

- branching as follows:

- complex nucleus: a long vowel as in CV: syllables: /kara:si/ chairs and /reg.le:/ 'his legs'. 
- $\quad$ simple nucleus + simple coda

as in CVC syllables: /yih.gim/ he attacks and /saS.tak/ your (m. sing.) watch.

- simple nucleus + complex coda as in CVCC syllables: /?ibn/ son and /?ism/ name.

- complex nucleus + simple coda as in CV:C syllables: /Gi:d/feast/mo:z/ bananas and /be:t/ home.

- complex nucleus + complex coda as in CV:CC syllables, which commonly occur in Classical Arabic, but less frequently in CCA: /ma:rr/ passer-by and /ha:mm/ important.

CCA Rime Parameters:

- non-branching? (yes)

Restrictions: $\quad$ simple nucleus with $\mathrm{V}$

- branching? (yes)

Restrictions: $\quad \mathrm{CV}:, \mathrm{CVC}, \mathrm{CVCC}, \mathrm{CV}: \mathrm{C}$ and $\mathrm{CV}: \mathrm{CC}$

CCA Rime Template:

$\mathrm{R}$ [VC], as in the CVC pattern

$\mathrm{R}$ [VCC], as in the CVCC pattern

$\mathrm{R}[\mathrm{V}]$, as in the $\mathrm{CV}$

$\mathrm{R}[\mathrm{V}:]$, as in CV: patterns

hence * $\mathrm{R}$ [VCCC]

In CCA, although all rime elements are stress bearers, only the nucleus bears the stress.

The syllable structure parameter settings of CCA are as follows:

VV nucleus allowed? No (but V: allowed)

$\mathrm{C}$ nucleus allowed?

No

Onset clusters allowed? No

Coda allowed? Yes

Coda Restrictions? Yes (not more than two)

For clarity, this is displayed in the following diagram:

(10) CCA Maximal Syllable:

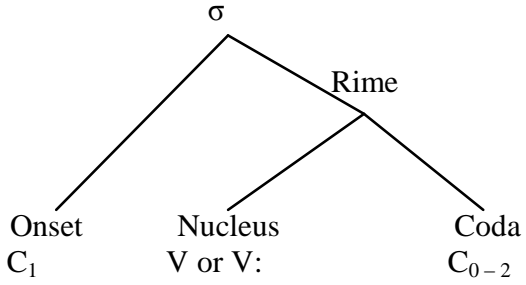

It is expected that syllabification differences between CCA and English lead to errors in main word stress placement by CCA speakers.

\section{CCA Syllable Types}

CCA syllable has been studied by many linguists (Brame, 1970; Broselow, 1979; McCarthy, 1979b; Selkirk 1981; among others), who find themselves in total agreement that the language's syllable inventory includes six syllable types: CV, CVC, CV:, CV:C, CVCC (Broselow, 1988, Buell, 1996) and CV:CC (Mitchell, 1960), as follows:

$\begin{array}{llll}\text { (11) } & \text { a. CV } & \text { /laban/ } & \text { 'milk' } \\ \text { b. } & \text { CV: } & \text { /sa:kin/ } & \text { 'inhabited (m. sg.)' } \\ \text { c. } & \text { CVC } & \text { /markaz/ } & \\ \text { d. } & \text { CV:C } & \text { /mida:n/ } & \text { 'centre' } \\ \text { e. } & \text { CVCC } & \text { /katabt/ } & \text { 'I wrote' } \\ \text { f. } & \mathrm{CV}: \mathrm{CC} & \text { /ma:rr/ } & \text { 'passer-by' }\end{array}$

The last three types usually appear at the end of a phonological word. In these last three types, the duration of the consonants and vowels are known to be longer than the other remaining types. The number of vowels and the number of syllables in an Arabic phrase must be equal. 
All the syllable structures in (11) exist both in Classical Arabic and in some modern dialects including CCA. CV is a light syllable, CV: and CVC are considered heavy syllables and CV:C and CVCC are superheavy syllables (Broselow, 1992). The first three types are considered by Al-Ani and May (1973) and McCarthy (1979) as unmarked in terms of their distribution, since they occur more frequently than CV:C, CVCC and CV:CC.

The internal structure of the six syllables above can be represented, as follows.

(12)

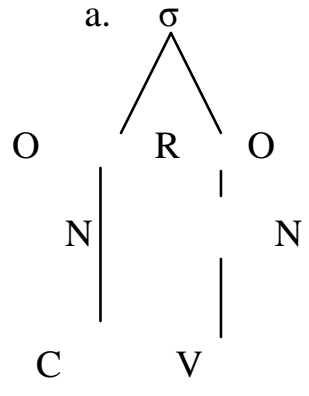

d. $\overbrace{\mathrm{R}}^{\sigma}$

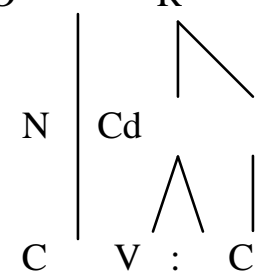

b.

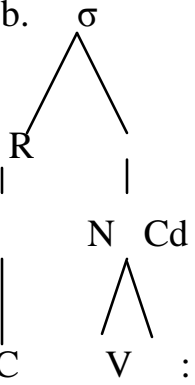

e.

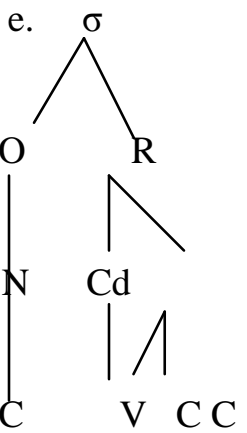

$\mathrm{O}$
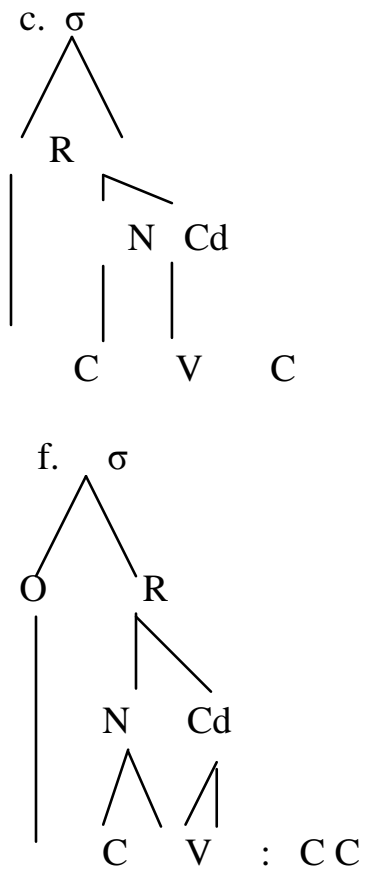

The structures in (12b) and (12c) are very similar - consisting of a simple onset and a branching rime. In (12b) the nucleus is branching with a long vowel without a coda, whereas in (12c) the rime contains a short vowel followed by a consonant.

The above CCA syllable types show the following:

- $\quad$ No syllable begins with a vowel, namely, onsets are obligatory (McCarthy and Prince, 1990).

- A syllable may contain either a short vowel as in (12a, c, e) or a long vowel as in (12b, d, f). But it never contains a diphthong.

- The rime may contain one, two or zero consonants.

CCA grammarians agree that, as in many Semitic languages, the CCA syllable takes one of the following forms: light, heavy and superheavy (Buell, 1996), as I show below.

(13) light $\mathrm{CV}$ (syllables with a non-branching rime)
/'bi/ 'in'
(CV)
/kata'bitu/ 'she wrote it'
/'buxala/ 'misers'
/'dawa/ 'medicine'
(CV CV CV CV)
/'malika/ 'queen'
$(\mathrm{CV} \mathrm{CV} \mathrm{CV})$
(CV CV)
$(\mathrm{CV} \mathrm{CV} \mathrm{CV})$

(14) heavy

a) CV: (syllables with a branching rime that dominates a long vowel)

/'ma:/'not (neg. particle)' (CV:)

/'ba:rid/'cold'

$(\mathrm{CV}: \mathrm{CVC})$

/'da:fi/'warm'

$(\mathrm{CV}: \mathrm{CV})$

/mi'ra:ti/ 'his wife'

/'Ja:ris/'street'

$(\mathrm{CV}: \mathrm{CVC})$

(CV CV: CV) 
b) CVC (syllables with a branching rime that dominates a vowel + consonant sequence)

$\begin{array}{llr}\text { /'min/ } & \text { 'from' } & \text { (CVC) } \\ \text { /mar'taba/ } & \text { 'mattress' } & \text { (CVC CV CV) } \\ \text { /'famfa/ } & \text { 'candle' } & \text { (CVC CV) } \\ \text { /'mufrif/ } & \text { 'supervisor' } & \text { (CVC CVC) }\end{array}$

(15) superheavy (syllables where a heavy rime is followed by a consonant)

a) $\mathrm{CVCC}$

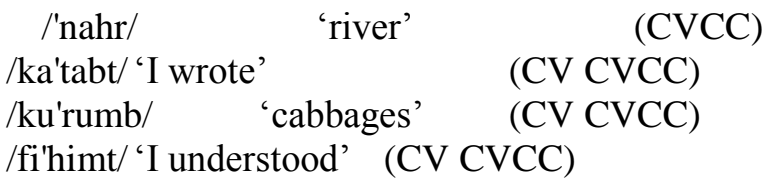

b) $\mathrm{CV}: \mathrm{C}$

$\begin{array}{ll}\text { /'ba:b/ 'door' } & \text { (CV:C) } \\ \text { /saka'ki:n/ 'knives' } & \text { (CV CV CV:C) } \\ \text { /sa'Ci:d/ 'happy' } & \text { (CV CV:C) } \\ \text { /bu'ju:t/ 'houses' } & \text { (CV CV:C) }\end{array}$

(16) Extraheavy (syllables where a heavy rime (V:) is followed by two consonants)

$\mathrm{CV}: \mathrm{CC}$

/sa:mm/ 'poisonous' (CV:CC)

/Sa:mm/ 'public' (CV:CC)

/ga:ff/ 'dry (adj.)' (CV:CC)

\subsection{Light Syllable}

The CCA light syllable is composed of a simple peak vowel, obligatorily preceded by a simple consonant onset. This CV syllable cannot be found as a monosyllabic word. This is the result of the minimal word restriction which requires CCA words to be bimoraic. CCA light syllables are CV (McCarthy and Prince, 1990). The CV type is the most frequent, natural and the least marked, whereas the CVCC is much less natural or more marked (Cairns and Feinstein 1982). The CV syllable is the minimal syllable type in CCA (Blevins, 1995).

\subsection{Heavy Syllable}

In CCA, a heavy syllable has a simple consonant onset and a branching rime. This rime incorporates either a one consonant coda (CVC) or a long-vowelled nucleus (CV:). The CV: type has some restrictions on its distribution. It is least frequent word finally, more frequent word medially and most frequent word initially (Watson, 2002). $\mathrm{CV}$ and $\mathrm{CVC}$ are the most frequent types because there are no restrictions of any kind on their distribution - they can occur in any position in the CCA word. CCA heavy syllables are CV: and CVC (McCarthy and Prince, 1990). The vowel in a CVC syllable must be fully pronounced - it cannot be reduced to another vowel.

\subsection{Superheavy Syllable}

CCA superheavy syllables are highly marked: they are limited to the word final position (Buell, 1996; Watson, 2002). McCarthy $(1979,452)$ states that the syllables CV:C and CVCC are "possible syllables of Cairene only in word-final position'. Broselow $(1992,10)$ explains the reason behind CCA superheavy syllable restriction to word-final position by stating that 'the restriction of superheavy syllables to morpheme-final position derives from the provision that only peripheral syllables may be 'incomplete', in accord with the widespread ability of peripheral elements to escape the structural restrictions operating elsewhere in a language by being marked extraprosodic'. The maximal word-internal syllables are heavy CV: and CVC. Superheavy syllables are composed of a heavy syllable plus a consonant: CV:C and CVCC. Prince $(1983,67)$ states that the superheavy ultima is naturally analyzed into two rimes $-\mathrm{VVC}=\mathrm{VV}+\mathrm{C}, \mathrm{VCC}=\mathrm{VC}+\mathrm{C}$ - since rimes may generally be at most $\mathrm{VV}$ or VC'. CCA superheavy syllables always attract main stress (de Lacy, 1998). 


\subsection{Extraheavy Syllable}

I suggest that CCA syllable types should include an additional extraheavy syllable which is CV:CC. This syllable type is the least frequent, since it is restricted to monosyllabic words. Mitchell $(1960,371)$ states that ' $\mathrm{CVVCC}$ is, in fact, rare and almost wholly associated with monosyllables'. This explains why many studies do not include this syllable in the basic repertoire of CCA syllable types - the unmarked types CV, CVC and CV:. The last consonant of the extraheavy syllable is always a geminate, as shown below:
/dza:rr/ 'pulling'
/xa:mm/
'raw'
/ha:mm/ 'important'
/Da:rr/ 'hurting'

The inventory of the possible syllables in CCA is shown below:

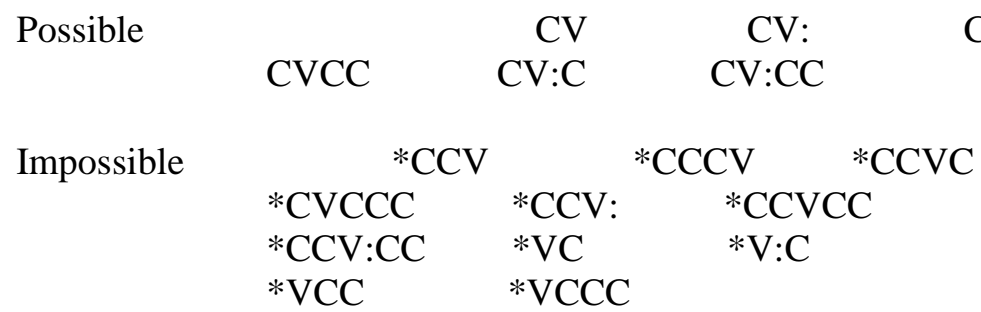

\section{English Syllable Structure}

\section{CVC}

This section deals with the structural constituents of the English syllable - onset, nucleus and coda - and their restrictions.

\subsection{Onset}

In English, onsets are optional (Hammond, 1999), in the sense that a syllable may or may not begin with a consonant, as shown below:

$\begin{array}{llll}\text { a. face each } & \text { b. ace } & & \text { each } \\ \text { meat miser } & \text { eat } & \text { area } \\ \text { cake feather } & \text { ache } & \text { upset }\end{array}$

The syllable structure of some of these words is as follows:
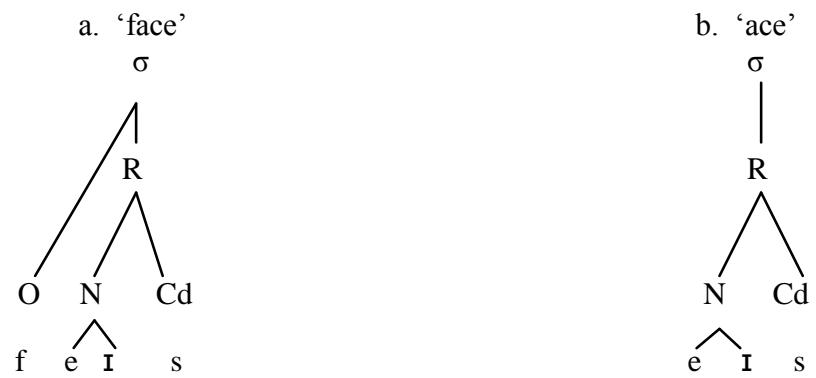

Harris $(1994,53)$ states that in English 'the onset can contain between zero and three positions'. The permissable English onsets, therefore, can take one of the following three forms:

- simple C: one consonant as in mind and rose.

- complex CC: two consonants as in play and trap.

- complex sCC: three consonants as in string and spleen.

English onset templates:

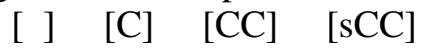

English onset parameters:

- onset (optional)

- onset clusters allowed? (yes)

- restrictions: not more than three consonants 
More specifically, the English onset may be (Hammond, 1999):

- absent - a sonorant - an obstruent

- an obstruent followed by a consonant

- or any of the above preceded by an /s/

- the minimal English onset is zero consonants (Harris, 1994).

- the maximal English onset is three consonants (Harris, 1994).

When English words are syllabified, the 'Onset Maximisation Principle' should be followed as far as possible (Harris, 1994): in English, maximal formation of onsets takes priority over formation of codas (Harris, 1994). This means that syllables should be divided, so that the maximum number of consonants is assigned to the onset of the syllable on the right, rather than to the coda of the syllable to the left, provided that they do not violate English phonotactic rules (Goldsmith, 1990), as shown in the following examples:

(20) Correct Syllabification

re.cruit /rr.'kru:t/

con.gress /'kpy.gres/

sur.prise /sə.'praiz/

\section{Incorrect Syllabification}

*rec.ruit /rik.'ru:t/

*cong.ress /'kpng.res/

*surp.rise /səp.'raIz/

These are the constraints on English onsets (Gimson, 1970):

- The two sounds $/ \mathrm{y} /$ and $/ 3 /$ cannot occur in the onset of any English syllable.

- The first consonant in a CCV syllable cannot be an affricate, $/ \mathrm{t}$, ds/ or a sonorant /m, n, y, l, r, w/ or an /h/ (Hammond, 1999).

- English CCCV syllables always begin with /s/ (Hammond, 1999).

\subsection{Nucleus}

The nucleus is the only obligatory constituent of the English syllable (Goldsmith, 1990). The English nucleus can take one of the following forms (Harris, 1994):

- $\quad$ simple (V): only one short vowel as in bed and cut.

- complex: as in one of the following shapes:

- (V:): only a long vowel as in see and blue.

- (VV): a diphthong as in cow and fly.

- (VVV): a triphthong as in flour and fire.

a syllabic consonant: a non-vocalic nucleus. Although English nuclei normally contain vowels, they can accept a sonorant consonant under pressure from the sonority profile of the segmental sequence, such as /l/ in bottle and middle, and the nasals $/ \mathrm{m} /$ and $/ \mathrm{n} / /$ as in rhythm and button respectively.

Correspondingly, the syllable structure is now exemplified:

(21) a. 'cut'

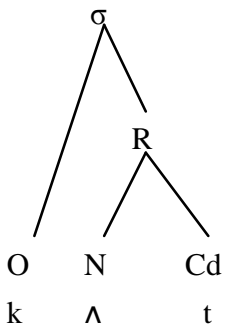

b. 'see'
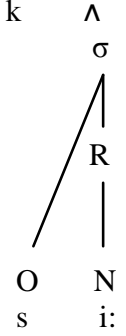
c. 'cow'

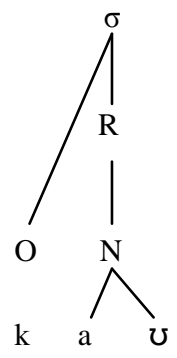

d. 'sour'
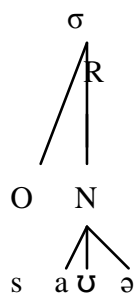

e. 'middle'

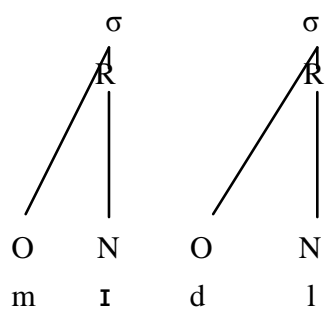

English nucleus parameters:

- V nucleus allowed? (yes)

- V: nucleus allowed? (yes)

- VV nucleus allowed? (yes)

- VVV nucleus allowed? (yes)

- C nucleus allowed? (yes)

English nucleus templates:
[V]
[V:]
[VV]
[VVV]
[C]

\subsection{Coda}

All consonants of English except [h] can appear as a single-consonant coda (Hammond, 1999). Harris $(1994,53)$ points out that in English 'the coda part of the rhyme can contain between zero and four positions'. Therefore, the English coda can have one of the following forms:

- Simple: one consonant, as in fit and red.

- Complex; as in one of the following shapes:

- CC: two consonants, as in lift and mind.

- CCC: three consonants, as in against and next.

- CCCs: four consonants, as in texts and sixths.

English coda parameters:

- coda allowed? (yes)

- coda clusters allowed? (yes)

- restrictions: medial (not more than two consonants)

final (not more than four consonants)

English coda templates:
[C]
[CC]
[CCC]
[CCCs] 
The minimal English coda is, therefore, one consonant, and the maximal four.The syllable structure is as follows:

(22) a. 'red'

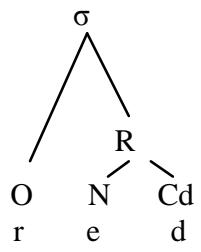

b. 'lift'

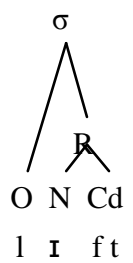

c. 'next'

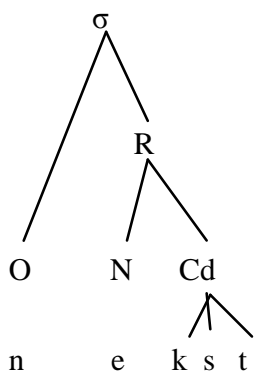

d. 'sixths'

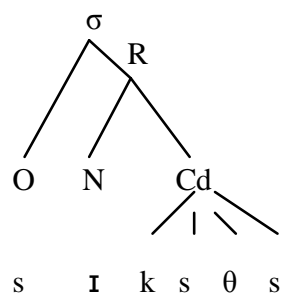

A different set of restrictions apply to coda consonants (Hammond, 1999):

- In one consonant codas, almost any consonant can occur (exceptions: /w, j, h/).

- In two consonant codas, the second must be an obstruent (wax, waft, adze etc.). (NB. nasal stops are not classed as obstruents (Trask, 1996)).

- Any of the above possibilities may be followed by an /s/.

- The minimal English coda is zero.

- The maximal English coda has four consonants, as in 'texts'.

\subsection{Rime}

The English rime can take one of the following forms (Hayes, 1995):

- Non-branching: it only includes a nucleus (V, V: or VV), without coda, as in banana, city, bee and play.

- Branching: as follows (Fudge, 1969; Selkirk, 1982; Goldsmith, 1990; Harris, 1994):

- $\quad$ simple nucleus + simple coda, as in hut and bit.

- $\quad$ simple nucleus + complex coda $\left(\mathrm{C}_{2-4}\right)$, as in song and felt / lifts and hands / tempts and contexts.

- complex nucleus + simple coda, as in feet and roof.

- complex nucleus + complex coda $\left(\mathrm{C}_{2-3}\right)$, as in feels, joint and waste / fields and points.

English rime parameters:

- non-branching? (yes) restrictions: nucleus with $\mathrm{V}, \mathrm{V}$ : or $\mathrm{VV}$

- branching? (yes) 
restrictions: $\quad \mathrm{VC}, \mathrm{VCC}, \mathrm{VCCC}, \mathrm{VCCCC}$

$\mathrm{VC}, \mathrm{VVC}$

$\mathrm{V}: / \mathrm{VV}+\mathrm{CC}$ or $\mathrm{CCC}$

English rime template:

$\begin{array}{llll}{[\mathrm{V}]} & {[\mathrm{VCC}]} & {[\mathrm{VCCC}]} & {[\mathrm{VCCCC}]} \\ {[\mathrm{V}: \mathrm{C}]} & {[\mathrm{VVC}]} & \\ {[\mathrm{V}: \mathrm{CC}]} & {[\mathrm{V}: \mathrm{CCC}]} & \\ {[\mathrm{VVCC}]} & {[\mathrm{VVCCC}]} & \end{array}$

Correspondingly, the structures are as follows:

(23) a. banana'

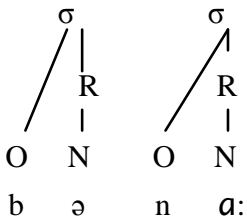

(24) a. 'hut'

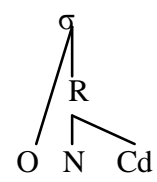

$\mathrm{h} \wedge \mathrm{t}$

c. 'hands'

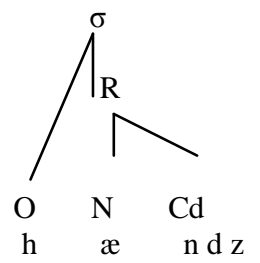

(25) a. 'feet'

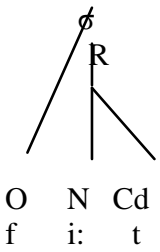

(26) a. 'joint'

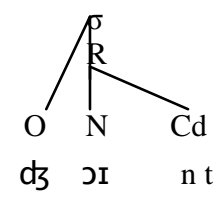

b. 'bee'

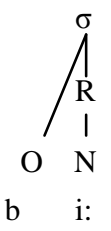

b. 'song'

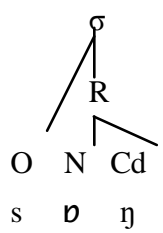

d.'tempts'

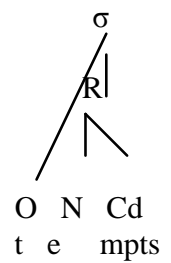

b. 'roof'

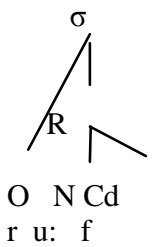

b. points'

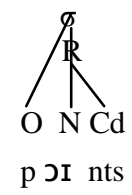

English has certain limitations on the form of heavy syllables.

- Long vowels and diphthongs can occur in both open (see /si:/, pay/peI/) and closed (team /ti:m/, weight /wert/) heavy syllables.

- Short vowels only occur in closed heavy syllables (fat /fæt/, ink/ink/). 
Heavy syllables have different types of rimes:

- a syllable ending in VC has a branching rime with a non-branching nucleus and coda, as in $\operatorname{sun} / \mathrm{s} \Lambda \mathrm{n} /$ and got /gpt/.

- a syllable ending in VV has a branching nucleus, as in tree /tri:/, and saw/so:/.

- a syllable ending in VVC has a branching rime with a branching nucleus, as in feet /fi:t/ and fall /fo:1/.

The corresponding rime structures of English heavy syllables are as follows:

(27)

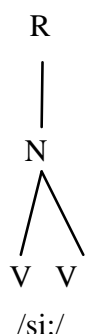

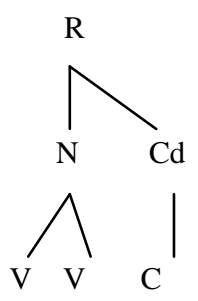

/si:t/

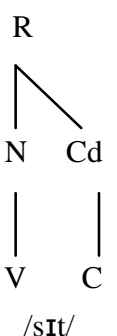

/sIt/

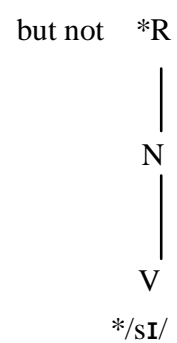

$* / \mathrm{sI} /$

In describing the phonotactics of the English syllable, linguists have focussed on restrictions concerning which phonemes may occupy which slots of the syllable. Research shows that in English CVC words, there is a significant connection between the vowel (nucleus) and the following consonant (coda) (Goldsmith, 2011). By contrast, no significant associations are found between the initial consonant (onset) and the nucleus.

\section{English Syllable Types}

English syllables are complex, and understanding them paves the way to understanding syllables universally. There are many types of syllable in English. English phonotactics show that the basic configuration or template of an English syllable is $(\mathrm{C}) \mathrm{V}(\mathrm{C})$, with an optional onset and coda and an obligatory nucleus. It is therefore, the nucleus, that is the essential part of the rime and of the whole syllable.

English can thus have a syllable that does not have a coda and therefore ending in a vowel, having an open syllable with the $(\mathrm{C}) \mathrm{V}$ - structure, and a syllable with a coda and therefore ending in a consonant, a closed syllable - of the type (C)VC-. In English open and closed syllables are clearly related to weight - open syllables can be heavy (CVV) or light (CV) and closed syllables are always heavy (CVC, VC, VCC etc.):

a. open heavy syllable CVV

b. closed heavy syllable VCC

c. light syllable CV (always open)

In English word phonotactics are based on syllable phonotactics. This means that only clusters which can begin a syllable can begin a word and only a possible cluster at the end of a syllable can end a word. A word like 'instruct' can be divided into well-formed syllables /in.struct/ because the word final and initial syllables consist of possible constraints in English.

English has the following syllable structure parameter settings:

VV/V: nucleus allowed? Yes

C nucleus allowed? Yes

Onset clusters allowed? Yes

Coda allowed? Yes

Coda restrictions? Yes (not more than four)

Structurally, the English syllable can be described as having the maximal length CCCVCCCC, as in 'strengths', and the minimal length V, as in the first syllable in 'e.ver'. It follows that no English syllable or word begins with more than three consonants and ends with more than four consonants (Harris, 1994), where the first and last consonants must be /s/, as in 'strengths'. For clarity this is displayed in the following diagram: 


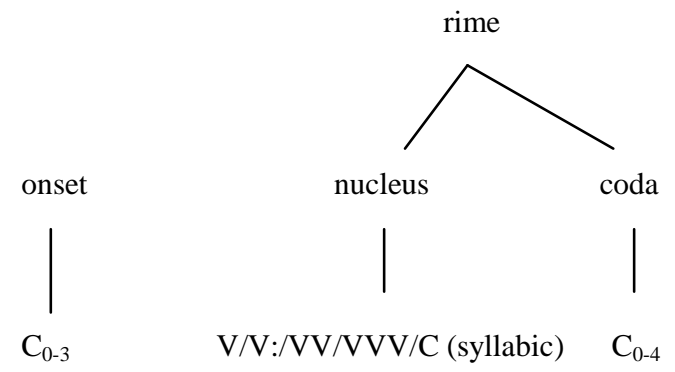

The following inventory illustrates all the possible English syllables:

\begin{tabular}{|c|c|c|c|c|}
\hline \multirow[t]{8}{*}{ (30) Possible } & \multirow[t]{2}{*}{$\begin{array}{l}\text { V } \\
\text { e.ver }\end{array}$} & \multirow{2}{*}{$\begin{array}{l}\mathrm{CV} \\
\text { to } \\
/ \mathrm{t} v /\end{array}$} & \multirow{2}{*}{$\begin{array}{l}\mathrm{CCV} \\
\text { cri.ti.cise } \\
\text { /krI.tI.saIz/ }\end{array}$} & \multirow{2}{*}{$\begin{array}{l}\text { CCCV } \\
\text { stra.te.gic } \\
\text { /stræ.ti:.d3Ik/ }\end{array}$} \\
\hline & & & & \\
\hline & $\begin{array}{l}\mathrm{VC} \\
\text { at }\end{array}$ & $\begin{array}{l}\text { CVC } \\
\text { hot }\end{array}$ & $\begin{array}{l}\text { CCVC } \\
\text { skin }\end{array}$ & $\begin{array}{l}\text { CCCVC } \\
\text { strap }\end{array}$ \\
\hline & /at/ & /hot/ & /skIn/ & /stræp/ \\
\hline & $\begin{array}{l}\text { VCC } \\
\text { apt }\end{array}$ & $\begin{array}{l}\text { CVCC } \\
\text { desk }\end{array}$ & $\begin{array}{l}\text { CCVCC } \\
\text { trains }\end{array}$ & $\begin{array}{l}\text { CCCVCC } \\
\text { strand }\end{array}$ \\
\hline & /æpt/ & /desk/ & /treInz/ & /strænd/ \\
\hline & $\begin{array}{l}\text { VCCC } \\
\text { ants }\end{array}$ & $\begin{array}{l}\text { CVCCC } \\
\text { desks }\end{array}$ & $\begin{array}{l}\text { CCVCCC } \\
\text { sphinx }\end{array}$ & $\begin{array}{l}\text { CCCVCCC } \\
\text { strangle }\end{array}$ \\
\hline & /ænts/ & /desks/ & /sfInks/ & /strængl/ \\
\hline & $\begin{array}{l}\text { Cs C } \\
\text { angsts } \\
\text { /æysts/ }\end{array}$ & $\begin{array}{l}\text { CCs } \\
\text { tempts } \\
\text { /tempts/ }\end{array}$ & $\begin{array}{c}\text { CCVCCCs CC } \\
\text { twelfths } \\
\text { /twelf } \theta \text { s/ }\end{array}$ & $\begin{array}{l}\text { VCCCs } \\
\text { strengths } \\
\text { /streyges/ }\end{array}$ \\
\hline Impossible & \multicolumn{2}{|c|}{$\begin{array}{ll}* \mathrm{CCCCV} & * \mathrm{VCCCCC} \\
* \mathrm{VVCCCC} & * \mathrm{CCCCVV}\end{array}$} & \multicolumn{2}{|c|}{ *VVCCCCC } \\
\hline
\end{tabular}

In English, onsets, nuclei and codas may have more than one constituent, and each constituent occupies a single slot. Therefore, a diphthong or a long vowel in a complex (branching) nucleus will occupy two slots. Similarly, each consonant in a complex onset or coda will occupy a single slot. This is shown in the English syllable ground /graond/, in which all three elements branch:

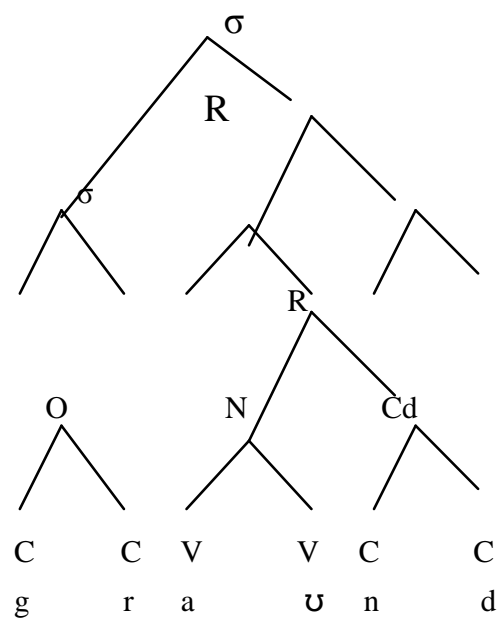

There is one exception to the rule that a syllable must have a vowel as its nucleus. This occurs when a certain vowel-like consonants - /l/, /r/ or a nasal- act as the centre of the syllable, as in the following examples.

little /1/ button $/ \mathrm{n} /$

middle /l/ literal /r-1/

rhythm $/ \mathrm{m} / \quad$ Hungary $/ \mathrm{r} /$ 
This is shown in the English word 'little' where the final [1] is syllabic.

(32)

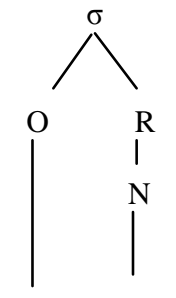

1

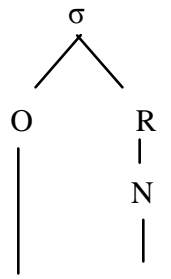

5.1 Light Syllable

An English light syllable is a syllable with neither a long nucleus nor a coda (Blevins, 1995) as in 'camera' and 'salary'. This syllable is referred to as CV and is considered as an open syllable, as shown below in a tree representation of the English word 'cinema'.

(33) English Light Syllable:
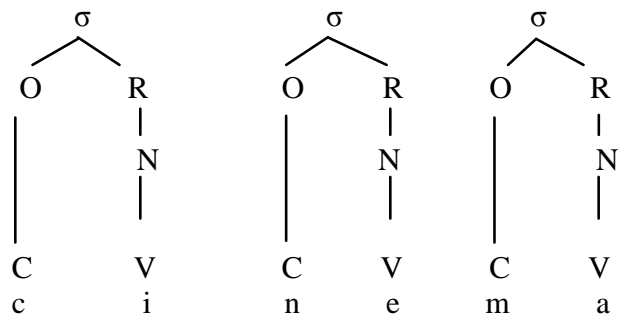

There are many words in English that have light syllables as part of their syllabic structure, as shown below.

$\begin{array}{rlr}\text { (34) a. } & \text { 'colony } & \text { 'negative } \\ \text { 'comedy } & \text { 'minimal } \\ \text { 'cavity } & \text { 'positive } \\ \text { b. } & \text { gra'mmatical } & \text { 'ceremony } \\ \text { pho'tographer } & \text { pa'rameter } \\ & \text { 'relevant } & \text { capa'bility }\end{array}$

The examples in (34) have light syllables, with one of them in every word receiving stress. However, the location of stress in English depends on the distribution of heavy syllables and their rime structures as explained in section (6) which compares CCA and English syllable structures.

\subsection{Heavy Syllable}

The definition of a heavy syllable is language-specific in the sense that it varies from one language to another (Hayes, 1995). In English, a heavy syllable is a syllable with a branching nucleus or a branching rime. A branching nucleus means the syllable has a long vowel as [i:] in 'in'crease' or a diphthong as [aI] in 're'ply'. This syllable referred to as CVV or CV: and is considered as an open syllable. A branching rime means the syllable has a coda, as [t] in 'hat' and [n] in 'a'genda'. This syllable is referred to as (VC, CVC, CVCC etc.) is considered a closed syllable. The two types of English heavy syllable are shown below in a tree representation of the English words 'pen', 'pay' and 'pea'. 
(35) (35) English Heavy Syllable:

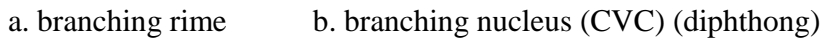
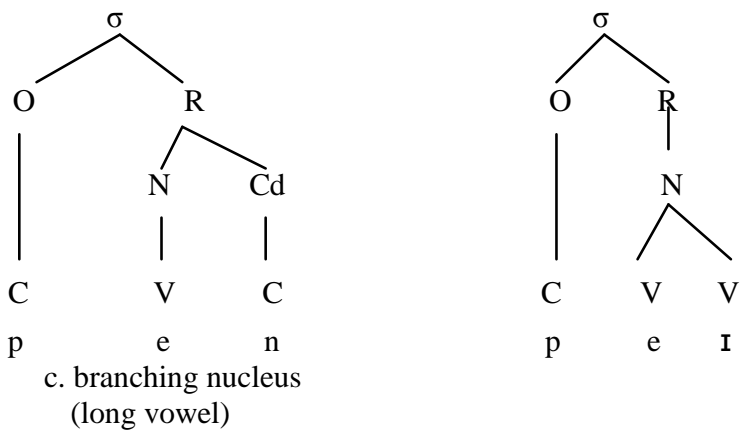

(long vowel)

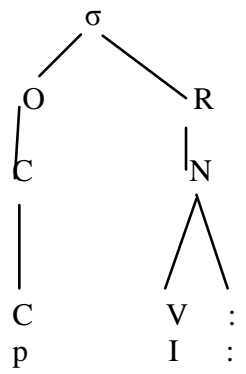

I

English has many words that include a heavy syllable in different positions, as shown in the examples:

\begin{tabular}{|c|c|c|c|c|}
\hline$(36(36)$ & $\begin{array}{l}\text { a. res'pect } \\
\text { re'member } \\
\text { de'termine }\end{array}$ & $\begin{array}{l}\text { a'bandon } \\
\text { re'minder } \\
\text { de'pendant }\end{array}$ & $\begin{array}{l}\text { b. 'way } \\
\text { 'say } \\
\text { be'have }\end{array}$ & $\begin{array}{l}\text { 'play } \\
\text { 'stay } \\
\text { pro'vide }\end{array}$ \\
\hline c. & $\begin{array}{l}\text { 'see } \\
\text { 'we } \\
\text { 'bee }\end{array}$ & $\begin{array}{l}\text { de'crease } \\
\text { 'teacher } \\
\text { 'sheep }\end{array}$ & & \\
\hline
\end{tabular}

The examples in (36a) have a heavy syllable with a branching rime, whereas the ones in (36b and c) have a heavy syllable with a branching nucleus - a diphthong and a long vowel, respectively. All these examples show that a heavy syllable has a relationship with stress placement in English.

\section{Implications for L2 English Syllable Acquisition}

In this section, the similarities and differences between CCA and English syllable structures are compared and the previous description is translated into parameter settings, following Fikkert (1994). This explains the distance between CCA and English syllable structures.

The similarities and differences between CCA and English syllable structures are summarized in Table 2.

Table 2: CCA and English Syllable Structures

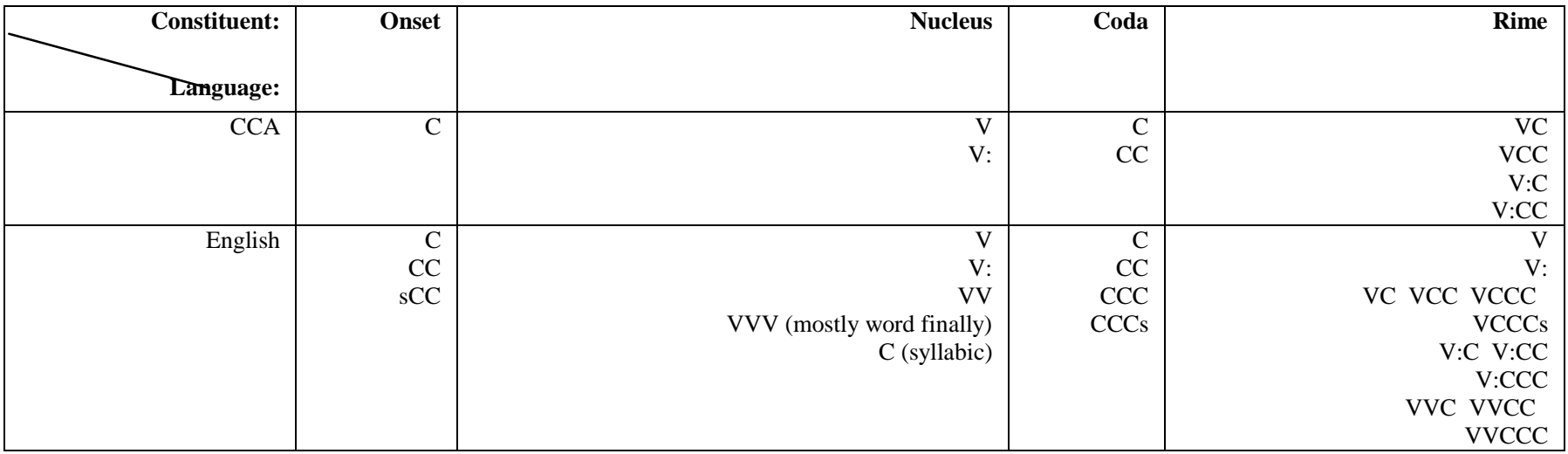

Each syllable constituent is now discussed in detail. 


\subsection{ONSET}

The differences between English and CCA onsets are represented graphically in (37):

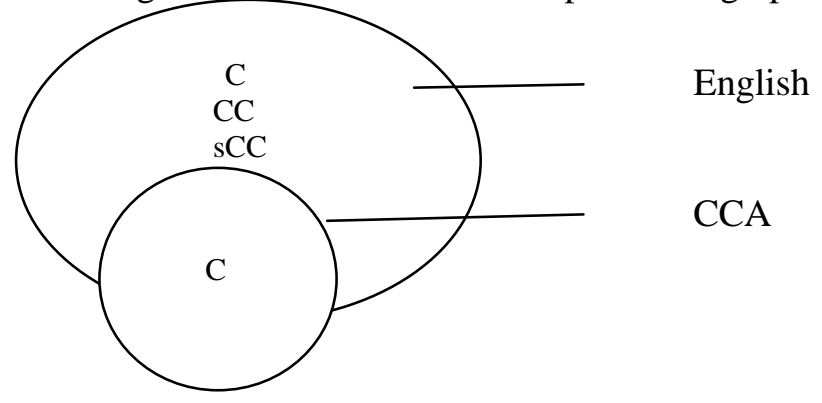

With respect to onsets, English allows the possible onset that CCA does and some more (i.e. the CCA onset is a subset of English onsets). More specifically, English allows a complex CC onset and an extrametrical element that is adjoined to the left of a well formed onset. This description can be expressed in terms of parameter settings, following Fikkert $(1994,108)$ who has suggested the following three settings for the onset parameter:

(38) Onset Parameter:

a. Number of onsets is equal to $1 \quad$ On $=1$

b. Number of onsets is equal to or smaller than $1 \quad$ On $\leq 1$

c. Number of onsets is equal to or smaller than $2 \quad$ On $\leq 2$ where $\mathrm{c} \longrightarrow \mathrm{b} \rightarrow$ a and means 'implies'

The default onset parameter setting would be a, since both CCA and English have the 'one consonant' onset parameter setting. Using L1 positive transfer of onset parameter setting, the Cairene learners will not find difficulty in producing 'the one consonant' English onset. The learners, however, will have difficulty in producing the two different English onsets (CC and sCC) and will have to find some strategies of L2 syllable repair in order to transfer these English onsets into acceptable CCA onsets. Broselow (1984) states that: (39) Errors nvolving consonant clusters generally occur when these clusters must be analyzed as belonging to syllable structures which are not permitted in the native language, and the mispronunciation of the clusters represents an attempt by the language learner to bring the second language forms into conformity with the first language restrictions defining possible syllables.

Epenthesis is the L2 syllable repair strategy used by the CCA speakers to deal with the English onset CC and sCC. They tend to insert epenthetic vowel [i] between the first and the second consonants of the English onset ' $\mathrm{CC}$ '. They also tend to insert a glottal stop plus epenthetic vowel /?i/ before the first consonant of this type of onsets in order to form an acceptable CCA syllable /CVC/.The first consonant will be the coda of the first syllable and the second consonant the onset of the second syllable, as shown below.

(40) Errors in English Onsets by CCA Speakers

(CC Onset)

$\begin{array}{ll}\text { English 'CC' Onset } & \text { Error } \\ \text { 'play } & * / \mathrm{bi} \text { 'lay/ } \\ \text { 'slide } & * / \mathrm{si} \text { 'laid/, /? is'laid/ } \\ \text { 'floor } & * / \mathrm{fi} \text { 'loor/, /? if'loor/ } \\ \text { 'criticise } & * / \text { kiriti'saiz/ }\end{array}$

When faced with the English onset 'sCC', the CCA speakers insert a /?i/ before the first consonant 's' forming a $\mathrm{CCA}$ syllable $/ \mathrm{CVC} /$ '? $\mathrm{is} /$, and then they break the ' $\mathrm{CC}$ ' cluster by inserting [i] between the 'CC', as shown below.

(41) Errors in English Onsets by CCA Speakers (sCC Onset)

English 'sCC' Onset $\quad$ Error

street

*/?isti'ri:t/, /sit'ri:t/

spring */?isbi'ring/

spleen $\quad * /$ ?isbi'leen/

splash */?isbi'lash/ 
As shown in (40) and (41), epenthesis leads to resyllabification of the English words and change of main word stress location.

Finally, with respect to onsetless English words such as 'award', 'institute' and 'observe', the CCA speakers tend to insert a /?/ before the vowel, since onsetless syllables are impossible in CCA, as shown below.

(42) English Onsetless word Error

$\begin{array}{ll}\text { 'institute } & * / \text { ?inistit'ju:t/ } \\ \text { a'ward } & * / \text { ?'ward/ } \\ \text { 'applicant } & * / \text { ?appli'cant/ }\end{array}$

The Cairene learners, therefore, have to realize the following differences between English and CCA onsets:

(a) Onsets are optional in English but obligatory in CCA.

(b) CCA onset is a subset of English onsets.

(c) CCA onset must begin with one and only one consonant, whereas English can have complex onsets ('CC' or 'sCC') and simple onset ('C').

(d) In English 'onset maximization principle' should be followed as far as possible, Whereas, CCA only allows a single consonant onset.

\subsection{Nucleus}

The differences between English and CCA nuclei are represented graphically in (43):

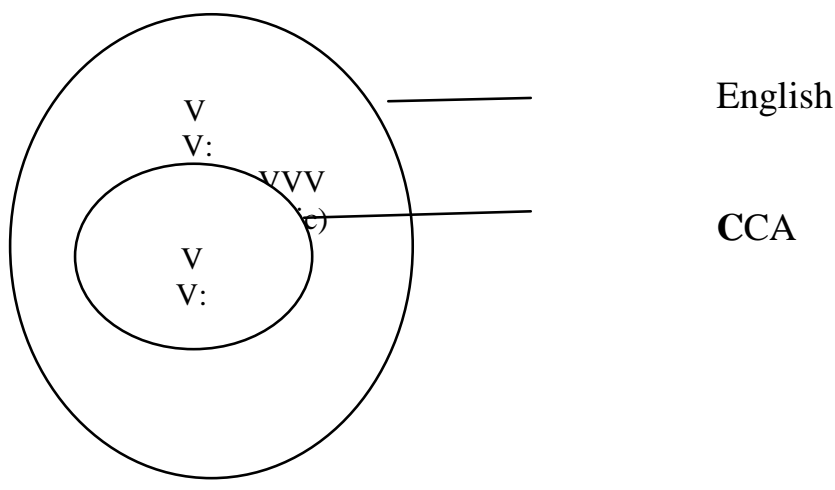

CCA nuclei are a subset of English nuclei. Both languages allow binary branching. However, an important difference between CCA and English nuclei is that in English the nucleus can be occupied by a long vowel (V:), a diphthong (VV) or a triphthong (VVV), whereas CCA does not have diphthong or triphthongs, so the binary branching can only involve a long vowel. English also allows a syllabic nucleus as $/ 1 /$ in 'bottle', /m/ in 'rhythm' and $/ \mathrm{n} /$ in 'button', whereas CCA does not allow this nucleus. Fikkert $(1994,108)$ suggests the following parameter:

(44) Branching Nucleus Parameter: The nucleus can be branching [No, Yes].

The default nucleus parameter setting would be (V) and (V:), since both CCA and English have two nuclei. Therefore, the Cairene learners will not find difficulty in producing the English nuclei (V) and (V:), if they positively transfer the L1 CCA nucleus parameter settings into the English nucleus parameter settings. However, the learners will find difficulty in producing the three different English nuclei (VV,VVV and syllabic C).Therefore, they are expected to produce the English VV and VVV nuclei as a V: nucleus and insert an epenthetic vowel [i] before the syllabic nucleus to form a CVC syllable as in 'middle', /middile/ and 'rhythm' /rhythim/. 


\subsection{CODA}

The difference between English and CCA codas are represented graphically in (45):

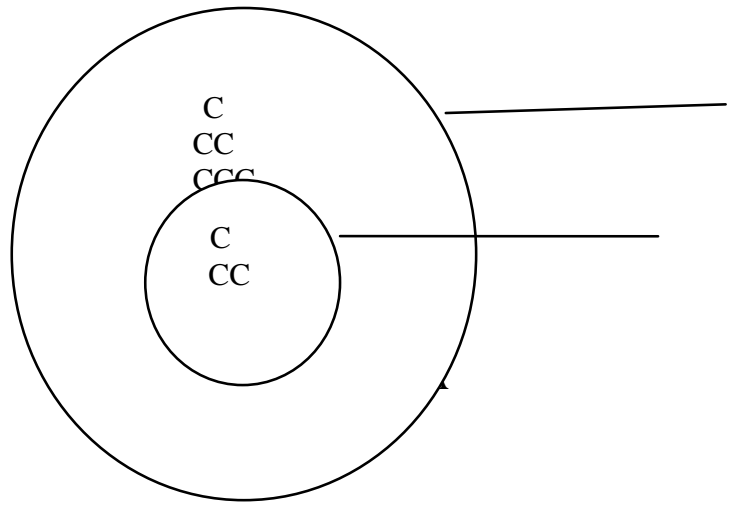

English

As in the case of onsets and nuclei, the CCA codas are a subset of English codas in the sense that English allows all the possible codas that $\mathrm{CCA}$ does and some more. In addition to $\mathrm{C}$ and $\mathrm{CC}$ codas, English has the complex codas CCC and CCCs as in 'strength' and 'tempts'. Therefore, it is expected that the Cairene learners will find difficulty in producing the English codas CCC and CCCs and will tend to break these consonant clusters by inserting an [i] before the final $\mathrm{C}$ in a $\mathrm{CCC}$ coda $/ \mathrm{CCiC}$ / as in 'strength' /strengith/ and between the $\mathrm{CC}$ and $\mathrm{Cs}$ in a CCCs coda /CCiCs/ as in 'tempts' /tempits/. This changes these English codas to similar CCA codas.

\subsection{RIME}

The differences between English and CCA rimes are represented graphically in (46):

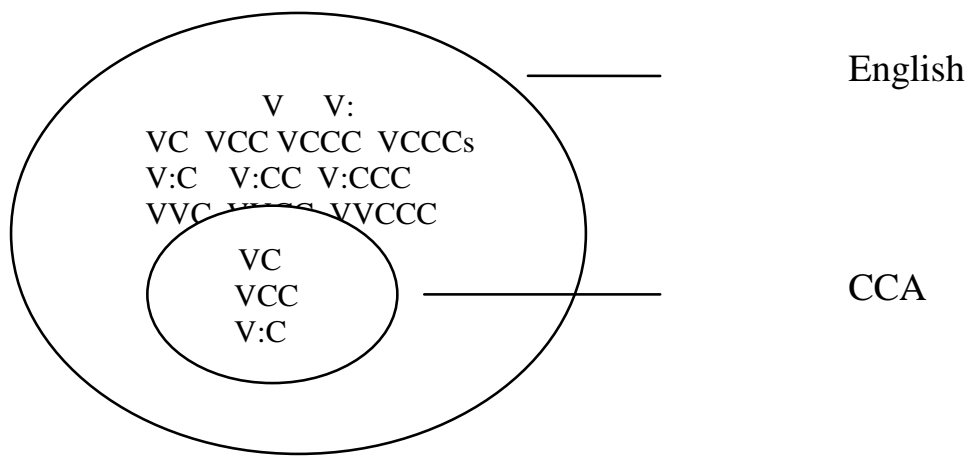

As in the case of onsets, nuclei and codas, CCA rimes are a subset of English rimes. English allows all the possible CCA rimes and some more. In addition to $\mathrm{VC}, \mathrm{VCC}, \mathrm{V}: \mathrm{C}$ and $\mathrm{VVC}$ and the complex rimes, English has the rimes V, V:, VCC and the complex rimes VCCC, VCCCs, V:CCC, VVCC and VVCC. Following Fikkert (1994), we add the following maximal rime parameter:

(47) Maximal Rime parameter:

a. The maximal number of rime consonants is $=1$

b. The maximal number of rime consonants is $\leq 2$

c. The maximal number of rime consonants is $\leq 3$

$\mathrm{d}$. The maximal number of rime consonants is $\leq 4$

where $\mathrm{d} \rightarrow \mathrm{c} \rightarrow \mathrm{b} \rightarrow \mathrm{a}$ and means 'implies'

The English setting would be $\mathbf{d}$ and the CCA setting would be $\mathbf{b}$. Therefore, it is expected that the Cairene learners of L2 English will find difficulty in producing the English complex rimes which end in $\mathrm{C}_{3-4}$, since CCA only allows rimes with a maximum of two consonants. They, therefore, will tend to insert an [i] before the final $\mathrm{C}$ in a $\mathrm{CCC}$ coda $/ \mathrm{CCiC}$ and between the $\mathrm{CC}$ and $\mathrm{Cs}$ in a $\mathrm{CCCs}$ coda $/ \mathrm{CCiCs} /$ in order to form acceptable rimes in CCA.

The relationship between rime structure and main stress placement in CCA and English is now explained.

Table (3): Rime Structure and Main Stress in CCA (based on Langendoen (1968, 102) and McCarthy $(1979,447))$ 
Table (3): Rime Structure and Main Stress in CCA (based on Langendoen $(1968,102)$ and McCarthy $(1979,447))$

\begin{tabular}{|c|c|}
\hline & \\
\hline & \\
\hline & $\begin{array}{l}\text { Final superheavy or heavy } \\
\text { CV: }\end{array}$ \\
\hline$\tilde{E}^{ \pm}$ & Penultimate heavy \\
\hline 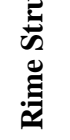 & Penultimate light \\
\hline & \\
\hline
\end{tabular}

Table (4): Rime Structure and Main Stress in English (based on Roca and Johnson, 1999)

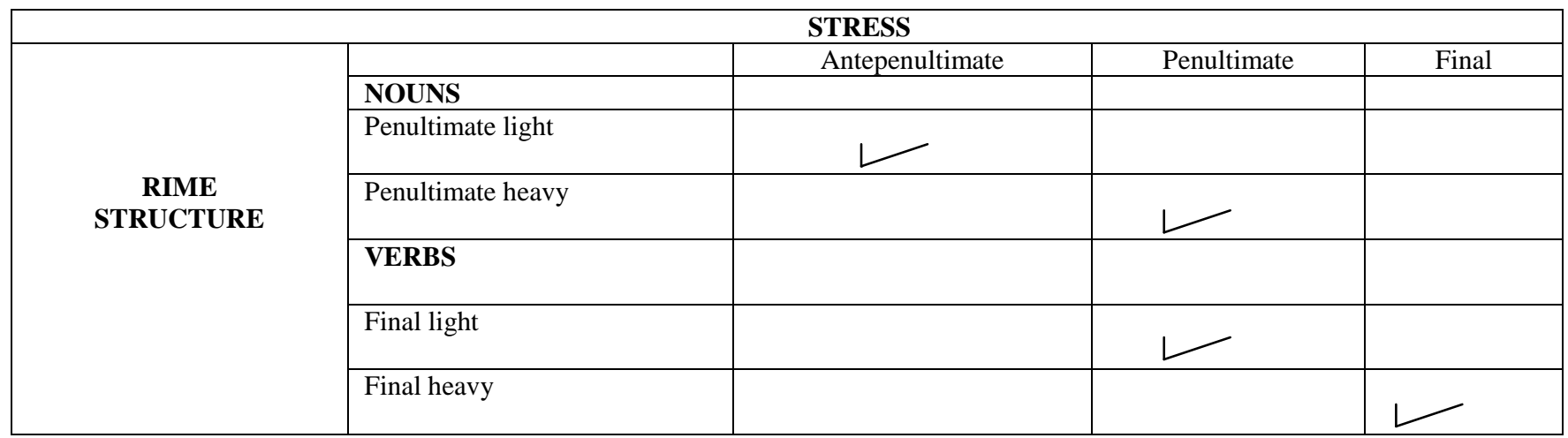

As shown in Table 3 and 4, syllable weight (rime structure) is an important factor in determining main stress placement in both CCA and English, since both languages are quantity sensitive. They are both similar in some points. First, if the penultimate syllable is heavy in CCA words and English nouns only, it is stressed. Second, if the final syllable is heavy CV: or superheavy CV:C/CVCC in CCA and heavy in English verbs only, it is stressed. Using positive transfer, the Cairene learners will not find difficulty in stressing English nouns having a stressed heavy penult and English verbs having a stressed heavy final syllable, if they realize the relationship between lexical class, rime structure and main stress placement in English.

CCA and English differ in the relationship between light syllables and main stress placement. In English nouns, if the penultimate syllable is light, the antepenult is stressed, whereas in CCA, if the penult is light, the penult or antepenult is stressed, whichever is separated by an even number of light syllables from the preceding heavy syllable or the beginning of the word if no heavy syllable (zero is counted as even). Therefore, it is expected that the Cairene learners will find difficulty in English nouns having a light penult, if they negatively transfer their L1 CCA rule by stressing a positionally defined light syllable (penult or antepenult).

\section{Conclusions}

A comparison of the CCA and English syllable structure constituents and their restrictions reveals the following: (a) CCA onsets, nuclei and codas are subsets of corresponding English syllable constituents. CCA maximal syllable is $\mathrm{C}_{1} \mathrm{~V} / \mathrm{V}: \mathrm{C}_{0-2}$ as in '/ga:ff/ 'dry', whereas English maximal syllable is $\mathrm{C}_{0-3} \mathrm{~V} / \mathrm{V}$ :/VV/VVVC $\mathrm{C}_{0-4}$ as in 'strengths'.

(b) CCA speakers attempt to pronounce and analyse the English strings according to the CCA rules. Therefore, they use syllable repair strategies to transfer the different English syllables into acceptable CCA syllables. For example, they pronounce 'street' as /?isti'ri:t/ or /sit'ri:t/ and 'institute' as /?inistit'ju:t/. This agrees with Broselow $(1984,263)$ 'Syllable Structure Hypothesis: When the target language permits syllable structures which are not 
permitted in the native, learners will make errors which involve altering these structures to those which would be permitted in the native language'.

(c) The role of the syllable must be taken into aacount while exaplaining the reasons behind the CCA speakers' errorsin L2 English. Broselow $(1984,267)$ states that 'thus phonetic rules, particulary rules involving syllable structure, appear to play a role in both the production and the perception of second language strings. The recognition of the role of these rules in second language acquisition makes possible an account of many learner errors as a result of transfer'.

(d) Syllable weight is an important factor in determining main stress in both CCA and English, since both languages are quantity sensitive.

\section{References}

Al-Ani, S. and D. R. May (1973). The Phonological structure of the syllable in Arabic. American Journal of Arabic Studies 1, 113-135.

Archibald, J. (1998). Second Language Phonology. Amsterdam, Philadelphia: John Benjamins Publishing Company.

Blevins, J. (1995). The syllable in phonological theory. In John Goldsmith (ed) The Handbook of Phonological Theory, (pp. 206-244) $1^{\text {st }}$ Edition. Oxford:Blackwell.

Brame, M. (1970). Arabic Phonology: Implication for Phonological Theory and Historical Linguistics. Doctoral dissertation, MIT.

Broselow, E. (1976). The Phonology of Egyptian Arabic. PhD dissertation, University of Massachusetts, Amherst.

Broselow, E. (1979). Cairene Arabic syllable structure. Linguistic Analysis 5, 345-382.

Broselow, E. (1984). An investigation of transfer in second language phonology. International Review of Applied Linguistics 22: 253-269.

Broselow, E. (1988). Second language acquisition, in F. Newmeyer ed., Linguistics: The Cambridge Survey, Volume III: 194-209. Cambridge: Cambridge University Press.

Broselow, E. (1992). Language transfer and universals in second language epenthesis, in S. Gass and L. Selinker, eds., Language Transfer and Language Learning: 71-86. Amsterdam: John Benjamins.

Buell, L. (1996). A footless, constraint-based analysis of stress in Cairene Arabic. Linguistics: 195.

Cairns, C. E and M. H. Feinstein (1982). Markedness and the theory of syllable structure, Linguistic Inquiry 13/2: 193-225.

Chomsky, N. and M. Halle (1968). The Sound Pattern of English. New York: Harper and Row.

Clements, G and S. Keyser (1983). CV Phonology: A Generative Theory of the Syllable (Linguistic Inquiry Monographs). MIT Press.

Crystal, D. (1997). A Dictionary of Linguistics and Phonetics: $4^{\text {th }}$ Ed. Blackwell.

de Lacy, P. (1998). Sympathetic Stress, ROA-294.

Fikkert, P. (1994). On the Acquisition of Prosodic Structure. PhD dissertation Holland Institute of Generative Linguistics, Leiden University, Holland Academic Graphics.

Fudge, E. (1969). Syllables. Journal of Linguistics 5, 253-286.

Giegerich, H. (1992). English Phonology: An Introduction. Cambridge University Press.

Gimson, A. (1970). An Introduction to the Pronunciation of English, $3^{\text {rd }}$ edition, Edward Arnold.

Goldsmith, J. (1976). Autosegmental Phonology. PhD dissertation, MIT, Cambridge, Massachusetts.

Goldsmith, J. (1990). Autosegmental and Metrical Phonology. Oxford and Cambridge, MA: Basil Blackwell.

Goldsmith, J. (2011) The Syllable, in The Handbook of Phonological Theory, $2^{\text {nd }}$ Edition Edited by John Goldsmith, Jason Riggle and Allan C.L.Yu. Oxford: Wiley-Blackwell.

Halle, M. and J. Vergnaud (1987). An Essay on Stress. MIT, Cambridge, MA.

Hammond, M. (1999). The Phonology of English: A Prosodic Optimality-Theoretic Approach, Oxford University Press, New York.

Harris, J. (1994). English Sound Structure. Oxford/Cambridge, Mass: Blackwell.

Hayes, B. (1995). Metrical Stress Theory: Principles and Case Studies. University of Chicago Press.

Hooper, J. (1972). The Syllable in Phonological Theory, Language 48: 525-540.

Itô, J. (1989). Prosodic Theory of Epenthesis. Natural Language and Linguistic Theory 7:217-259

Khan, D. (1976). Syllable-based Generalisations in English Phonology. PhD. dissertation, MIT, Massachusetts. Langendoen, D. T. (1968). The London School of Linguistics. Cambridge, MA: MIT Press. 
Laver, J. (1994). Principles of phonetics, Cambridge textbooks in linguistics, Cambridge; New York, NY: Cambridge University Press.

Liberman, M. and A. Prince (1977). On stress and linguistic rhythm. Linguistic Inquiry 8, 249-336.

Malmberg, B. (1963). Phonetics. New York: Dover Publications.

McCarthy, J. (1979). On stress and syllabification. Linguistic Inquiry 10: 443-466.

McCarthy, J. and A. Prince. (1990). Foot and word in prosodic morphology: the Arabic broken plural, Natural Language and Linguistic Theory 8, 209-83.

Mitchell, T. F. (1960). Prominence and syllabification in Arabic, Bulletin of the School of Oriental and African studies 23, 369-89. [Reprinted in Mitchell 1975a, pp. 75-98.]

Pike, K. (1947). Grammatical Prerequisites to Phonemic analysis. Word 3: 155-172.

Prince, A. (1983). Relating to the grid. Linguistic Inquiry 14: 19-100.

Prince, A. and J. McCarthy (1996). Prosodic Morphology. RuCCS-TR-32. Rutgers Center for Cognitive Science.

Prince, A. and P. Smolensky (1993): Optimality Theory: Constraint Interaction in Generative Grammar. Rutgers University Center for Cognitive Science.

Pulgram, E. (1970). Syllable, Word, Nexus, Cursus. The Hague: Mouton.

Roach, P. (2000). English Phonetics and Phonology, a Practical Course. Cambridge University Press.

Roca, I. and W. Johnson (1999). A Course in Phonology. Oxford: Blackwell.

Selkirk, E. (1981). Epenthesis and degenerate syllables in Cairene Arabic. In H.Borer and Y. Aoun (eds.), Theoretical Issues in the Grammar of Semitic Languages. MIT Working Papers in Linguistics 3: 209232.

Selkirk, E. (1982).TheSyllable.Invan der Hulst and N. Smith eds., The Structure of Phonological Representations, Part II: 337-383.

Spenser, A. (1996). Phonology: Theory and Description. Oxford: Blackwell Publishers.

Trask, R. (1996). A Dictionary of Phonetics and Phonology. London, Routledge.

Watson, J.C.E. (2002). The Phonology and Morphology of Arabic. Oxford University Press, London. 